\title{
Induction and Socialization of New Teachers in Institutional Schools
}

\section{Dhanapati Subedi* and Beni Bahadur Karkee}

The Department of Educational Leadership, Kathmandu University School of Education, Hattiban, Lalitpur, Nepal

\section{Abstract}

The purpose of this paper is to explore how schools in Kathmandu practice the ideas of induction and socialization among new teachers appointed to the organization. The major focus is on exploring how newly hired employees become adjusted to the organization's culture, their work group, and how they learn the information necessary for effective job performance. The paper is developed on the basis of information collected through narrations shared during our interviews with administrators, human resource managers and teachers in the institutional schools of Kathmandu based on few guiding ideas like: framework institutions apply for teachers' induction and socialization during the transition and the issues and challenges inherent in the teacher induction process. In our engagement with the participants, we understood that the new entrants tend to struggle with their tasks; are seemingly nervous of the new work challenges, and tend to fail in conducting day-to-day activities in the absence of proper orientation about the job they are supposed to perform. Therefore, we conclude induction and socialization as strategic human resource management tools that help employees to connect to the new working environment through their head and heart. It could have direct influences on the quality of work expected from the new intake. Thus, it is undeniable that only those new intakes who are well oriented about organizational goals, who have prior information as to what is expected of them, who possess

\footnotetext{
* Corresponding should be addressed to Dr Dhanapati Subedi, Department of Educational Leadership, Kathmandu University School of Education, Hattiban, Lalitpur, Nepal
}

Email:dpsubedi@kusoed.edu.np

(Dttps://orcid.org/0000-0002-4900-434X

(Received $1^{\text {st }}$ March 2020; Revised $4^{\text {th }}$ September 2020; Accepted $15^{\text {th }}$ September 2020 (C) OUSL) 
mechanisms to counter their early anxiety through familiarizing themselves with the working environment with the help of senior staff are able to deliver the service as per the expectation of the organization.

Keywords: induction and socialization, New teachers, Institutional School, Human Resource Management

\section{Setting the scene}

In the process of recruiting new teachers, suggests Kelley (2004), it is important that the organizations taking in these new employees have good strategic plans for induction and socialization of the new comers so that they experience comfort in their new work place. According to Feiman-Nemser (2001), "Sink or swim" induction encourages novices to stick to whatever practices that enable them to survive whether or not they represent 'best' practices in that situation". Therefore, teacher induction programs are of essential value to the development and quality of novice teachers.

Having spent a long time working in the organizational setting of institutional schools in Nepal, we have seen and experienced teachers facing enormous challenges in their workplace. At times such difficulties arise because of being a new employee in the new organization with new structure, goals and objectives. It could also happen as a result of friction in relationship among the senior staff or one's own confusion in the initial days to exactly adjust to the new environment. Whatever the reasons are, it is a fact that new employees struggle to experience the perceived advantages and comforts of a new work place. Among many causes, one could be the lack of proper induction and socialization strategies in the institutional schools in Nepal because of which the new employees go through this tough task of breaking the preexisting constrains to develop comfort zones and maintain good relationships among all.

Induction is the supportive introductory stage for new employees to settle quickly into their job and soon become active and efficient workers (Foot $\&$ Hook, 2011). The theory was initially formed in the United States and has been developed worldwide over the past few decades (Aswathappa, 2005). Based on Nankervis et al. (2009), induction is the final stage of recruitment and selection, and the first phase of training and employee development. The process of induction and socialization starts from the recruitment stage. It emphasizes the very first days of employees at work and continues throughout their development process in the company. The program can be different 
depending on the roles, status and the variety of program activities of the new employees (Wesson \& Gogus, 2005). Usually, the term induction is combined with orientation. There exists an assumption that the two concepts could be understood as a synonym. In fact, they vary in meaning and application. Induction signifies the comprehensive preview of the firm typically in a form of presentation, whereas orientation is the practical overview that comprises socialization and the learning-process. Orientation helps formalize and improve a new hire's level of comfort. In a nutshell, an induction and socialization program are organized by the HRD and conducted by every member of the company. It is the process of receiving employees, introducing them to their co-workers, facilitating and engaging them in organizational activities, customs, and traditions in the attempt to ease the transition they experience so that they have the wherewithal to cope with their instantaneous responsibilities. Such exposure should be a natural process when one steps in to a new environment and responsibilities (Khanduja, 2013).

People are motivated to personal performance, development and attachment only when their needs are fulfilled. The employees refuse to contribute to a company that they do not feel comfortable and secured within. Psychologically, need satisfaction, employees' performance, and retention strongly relate to each other (Huges et al. 2012). Therefore, affording employees' needs is essential for employers to maximize the profitability from human resources. Induction and socialization can be the prior step to reconcile and motivate employees into organizational operations. In other words, it could be a meaningful attempt in fulfilling the needs and expectations of the new employees. The understanding of employees' needs is required on behalf of employers to conduct the program successfully. In 1943, psychologist Abraham Maslow developed a theory that clarified five basic needs of a human in an organization. The theory is chosen because it clearly addresses the stage of employee needs that requires employers to fulfill early and, as is often the case, delaying them for a future time period. According to Maslow, every individual requires certain needs fulfilled in order to survive.

Through our own experience and observations of our colleagues experiencing the same difficulties, we have been inspired and motivated to work in this project to study and explore how schools in the Nepalese educational settings undertake the practices of conducting induction and socialization programs among new teachers who enter these organization with hopes of achievement. Based on our experiences as new teachers, where we faced disappointments that could have resulted in a pessimistic perception about the 
profession as a whole, we wanted to verify if our experiences hold true at present and if there are new experiences related to the same crisis. Therefore, to analyze the state of human resource development in the schools of Nepal in areas of induction and socialization of employees, we decided to visit few schools and interview the management, human resource department and teachers about their existing practices in their organizations so that their narratives could help us explore how schools have been contributing in the areas of employees' development on this specific area of induction and socialization.

\section{Background of the study}

Over the last two decades staff induction and socialization in organizations have advanced as a central topic in the field of HRM (Cable and Parsons, 2001). At the same time, this stream of research has also attracted increasing attention in mainstream management research particularly in relation to research on learning and knowledge sharing in organizations (Danielson, 2004). Thus, even in the Nepalese context, despite the subject gaining attention in educational research, the importance of organizations offering proper induction and socialization sessions to new employees seemingly has not been understood by many an education institution. On the other hand, it is also important that the organizations are empathetic when handling new human capital and induction and proper socialization programs can be the best mechanism to address this need. It can be a key process in ensuring that new employees effectively integrate into the organization that they are recruited.

Organizational socialization and induction refer to the learning process by which newcomers develop attitudes and behavior that are necessary to function as a fully-fledged member of an organization. Cable and Parsons (2001) describe induction as an arrangement made to familiarize the new employee with the organization, safety rules, general conditions of employment, and the work of the section or department in which they are employed. Organizational induction and socialization extend the action of introducing a new employee to the organization with the process of imparting the norms on how to behave in a way that is acceptable to the social group one joins.

In regard to the above-mentioned definition, it is important to draw attention to the importance of exploring the connections between staff induction, socialization and organizational recreation. It also becomes a necessity to highlight inter and intra practice dynamics of staff induction and socialization as part of a wider field of HRM practices. 
This can provide a basis for a more consistent and coherent pursuit of organizational development. In addition, the practice can contribute to promote reciprocity in the interaction that governs the way newcomers interact with the organization, their team, supervisors and their underlying values, rules, procedures and ways of doing things. Thus, we think it important to explore the HRM practice of induction and socialization in the schools of our social setting and critically review, analyze, and discuss the conceptual and empirical contributions to the staff induction and organizational socialization debate in our context. Therefore, the objective of this paper is to review the existing trend of HRM in this particular topic and highlight the main insights about these important organizational processes and practices, and also identify the critical extensions that could usefully be made to advance the debate in the field.

\section{Problem statement}

Human resource management strategies clearly position the need of induction and socialization as an essential tool for the proper mobilization of human capital to derive the desired goals and objectives of any organizations (Darsons, 2001). In the international context, there has been a great input from organizations in this matter. However, in the Nepalese context, the practice is new and is limited to few corporate organizations. Therefore, it is important that the very practice is taken to all organizations including institutional schools. Based on the significance of the topic, our paper focuses on exploring how schools in this context practice this HRM strategy through finding answers to the following problems:

- What is the current status of interpersonal behavior among teachers in institutional schools? How do they adjust in their new work place?

- What is the practice of human resource management strategies in addressing the areas of induction and socialization in institutional schools in Kathmandu?

We are interested to explore the ground realities in the abovementioned arguments and investigate the issue through interviews with new teachers and management in the institutional schools of Kathmandu.

\section{Purpose of the study}

The purpose of this paper is to explore the practice of induction and socialization for new teachers in the institutional schools with focus on understanding how teachers demonstrate socialization skills at 
their new work place and adapt to the new work environment to achieve what is expected of them.

\section{Research questions}

Based on the above purpose, the following research question has been formulated for the study:

How do teachers and management narrate the stories of their organizational practices related to induction and socialization strategies for newly recruited teachers?

\section{Rationale of the study}

This study is important in the field of education in the Nepalese context for a number of reasons. First, at some point, all new employees could have certain level of stress and anxiety as they walk into a new work place. They may be nervous in deciding where to start from and what to start with? It could be confusing to all about how to communicate with the senior staff and how to start building good interpersonal relations for effective team work. How to start building relationships with students in the new class? How does one begin to teach a lesson? All these questions could be difficult for a new teacher who has just walked into the organization. In this context, this paper will help both teachers and organization to ensure that they have preplanned strategies for induction and socialization so that an easy platform for the new comers to adjust in the new environment could be developed.

\section{Research Methodology}

This study employs qualitative approach to understand the ongoing practice of induction and socialization of new teachers in institutional schools from the perspective of the teachers, management and human resource department who work to coordinate the functioning of these employees. It is a qualitative research based in interpretative research design. Three participants for the research were taken through purposeful sampling and information from participants were collected through interviews. After generating narratives of the participants, they were transcribed into English language and then narratives of the participants were codded in order to develop themes out of them. Finally, meanings were made linking signature literature and relevant theories 


\section{Insights from the study}

The given chapter contains information collected from the research participants that are interpreted into different themes blending their stories to established literature. Based on the themes generated on the background of our participants' narrations, the practices of induction and socialization are explored using interpretative and reflective analysis. As researchers, our interpretation through understanding of the topic is also contained in this section of the paper.

\section{Theme 1: Employees expectation verses reality}

Participant 1: A newly recruited teacher in an institutional school said:

Teachers' induction and socialization program is very new to $m e$. This is my third organization that I recently joined and I have spent 9 (nine) years in this field already. Telling you openly, I am not very clear to the idea of induction and socialization.

From the explanation of the first participant, it can be understood that employees are confused about what induction and socialization is and what influences it could have in their work place. Furthermore, it seems like employees are also tend to misunderstand training and development programs with induction and socialization. This became even more prominent when the participant said, "Trainings and workshops are the only tool for human resource development in schools. In these nine years, I have attended almost around ten such programs. Let me share to you, though training and workshops are organized, our classrooms are not transformed as per the objectives of those programs and it just remains a learning least applied".

After our attempt to explain the topic to clear the participant's confusion, the participant presented his ideas explaining that his present organization had explained and oriented him to the job, facilities and work areas. He also shared the story where he was taken to the staff room and introduced to other members and was told about the perks, benefits and taught about the good prospects of professional growth in the organization.

Yes, I completely agree that application of proper induction and socialization technique will make employees feel better at their new work place. A new intake would be nervous, stressed and confused to take on with the responsibility from the very first 
day of appointment. So, it will help to develop better team spirit at work place.

From the above conversation, it can be stated that the participant acknowledges the importance of induction and how it could help to comfortably adjust at the new work place and better understand the goals and objectives of the organization and what one could expect from the institution and what is expected by the management from the employee when they are taken into the new work place. Furthermore, it would also help to update the members with organizational changes and developments (Armstrong, 2008).

Participant 2: A newly recruited teacher in an institutional school said:

It has been my privilege that I have always been a part of Agraded school in the town and wherever I have been I have always received a wonderful welcome in the new organization. I know how it feels to be at a new place and how imbalanced you are both psychologically and pathologically.

The above statement from the participant clearly states the need for empathy and assistance to cope with the new environment for all employees. In this case, induction and socialization could be an important tool to draw the best performance from the new intake. Furthermore, she described her transition where she explained how it had helped her to be well oriented and supported through good sessions by the senior team along with proper explanation of the organizational goals and objectives.

The comfort I been experiencing in my work place is because I am privileged to be well oriented about my job and my organizational expectations.

During her sharing, she also agreed with a narrative her friend, who remembered the difficulty she had in adjusting to her new work place and how often she complained about her immediate supervisor who did not take her problems seriously and how she had to work in a state of confusion, both in the areas of her immediate responsibilities and in maintaining good relations with her colleagues.

A friend of mine who is a fresher tells me about her struggle, $I$ can feel how it must have been for her to adjust in the new place. Often, she keeps complaining that her immediate manager doesn't properly explain what she is supposed to do and neither her old colleagues in the work place cooperate well. 
Thus, in this case, it is pretty evident that induction and socialization can be an effective human resource development tool to facilitate employees and make them comfortable at the new work place. On the other hand, the other teacher who has been struggling at her new place seems to lack proper orientation for her job and the organizational management seems to have failed to offer a proper induction program to help her.

\section{Theme 2: Induction and socialization can't be an option}

Participant 3: A Founder Principal of an institutional school said: It is common that new employees are usually perplexed, clumsy, slow, anxious and insecure on the first days of work. Their performance is often not as good as expected. The candidate can feel embarrassed, stupid, stressed, meaningless and hopeless. They worry about their performance and doubt their ability to "fit in." In the course of interview with the principal, he explained that during the induction, the instructors elaborated on the necessary information and knowledge the new teachers required to take on with their task at the new work place. For instance, the information included organization's overview, objectives, work portfolio, line managers, job-related techniques, technologies, legal requirements, key contacts and expectations in the form of standards.

I prepare job description as per the vacancy and recruitment is done on the basis of written tests and interview. During the selection process, I also keep along with me the in-charges from the respective areas to ensure that we make the best hire. After we feel that we have taken the best candidate from the process, we do take some days to orient the candidate about the organizational rules and regulations.

Besides, induction program plays motivational factors in long-term teacher retention. Induction program acclimates and engages a new employee with the organizational environment and culture. It displays their "duty of care" to arm the new employee with knowledge and skills so that he or she feels "fit in" and truly becomes a part of the organization. The participant stated, "The program can be different depending on the roles, status and the variety of program activities of the new employees. According to need, we also organize training sessions to employees whom we think is necessary to reorient about the job that will also include old teachers who are to be induced at times for better performance".

When the new hires are not well-prepared for practical situations, they easily panic and feel insecure when serving clients. The 
emotional instability effects their job performance-quality. In this case, they tend to have negative behaviors, pessimistic attitude and deficient job performance. Those people refuse to pay attention to their tasks and personal development to cope with the job requirements (Barrick, 2003). In this case, they seem to be off-track on the technique and could be doubtful about the quality of work expected of them. Hence, induction and socialization are important tools of strategic human resource management that inspire the new intakes and the senior ones to commonly pursue personal development and performance improvement in the future.

\section{Conclusions}

The induction program is a knowledge and information transfer process - a period of knowledge dissemination to equip the new entrants. The program aligns the new teachers with what the firm stands for and how it expects them to take on with their task from the very first day so as to meet the goals and objectives of the firm. Strategic application of induction and socialization techniques works as a motivational tool in building memorable impressions and positive inner feelings in employees towards the institution. The activity helps employees to connect to the new working environment in their head and heart. The program has direct influences on the quality of work expected from the new intake. A disoriented teacher tends to struggle in his/her tasks; tends to be nervous, and could fail in conducting day-today activities. Moreover, the new entrants need attention and courage to promote their emotional health or emotional stability. When new teachers feel supportive, oriented and active, they are willing to make a long-term commitment and remain within the organization. Therefore, based on this research, we conclude that induction and socialization is an integral aspect of strategic human resource management that can help employees to connect to the new working environment in their head and their heart. The program has direct influences on the quality of work expected from the new intake. It is undeniable that only well-trained newcomers can deliver the service as per the expectation of the organization.

\section{References}

Armstrong, M. (2008). Armstrong's Handbook of Strategic Human Resource Management. London: Kogan Page Limited

Aswathappa, K. (2005). Human Resource and PersonnelManagement. $4^{\text {th }}$ edition. New Delhi: Tata McGraw-Hill Education. 
Barrick, M. R. (2003). Conscientiousness and Emotional Stability. London: Blackwell Publishers.

Cable, D. M. \& Parsons, C.K. (2001). Socialization tactics and personorganization fit. Personnel Psychology.

Doi:10.1111/j.1744-6570. 2001.tb00083.x

Danielson, M. M. (2004). A theory of continuous socialization for organizational renewal. Human Resource Development Review, 3(4), 354-384. doi:10.1177/1534484304271528

Feiman-Nemser, S. (2001). From preparation to practice: Designing a continuum to strengthen and sustain teaching. Teachers College Record, 103, 1013-1055.

Foot, M., \& Hook, C. (2011). Introducing Human Resource Management, 6th edition. Edinburgh Gate: Pearson Education Limited.

Kelley, L. (2004). Why induction matters. Journal of Teacher Education, 55(5), 438-448. doi:10.1177/0022487104269653

Khanduja, M. (2013). Induction and Orientation. Retrieved June 15, 2015, from HR Dictionary: http://hrdictionaryblog.com/2013/01/22/induction-andorientation/

Wesson, M. J., \& Gogus, C. I. (2005). Shaking hands with a computer: an examination of two methods of newcomer organizational orientation. Journal of Applied Psychology, 1018-1026. Doi:10.1037/0021-9010.90.5.1018 